\title{
Erratum to: Growth of born globals: the role of the entrepreneur's personal factors and venture capital
}

\section{Elisa Ughetto ${ }^{1}$}

Published online: 28 July 2015

(C) Springer Science+Business Media New York 2015

\section{Erratum to: Int Entrep Manag J (2015) \\ DOI 10.1007/s11365-015-0368-1}

The original version of this article unfortunately contained a mistake. In Table 4 there are some mistakes in the association between significance and letters. The corrected table is presented below.

The online version of the original article can be found at http://dx.doi.org/10.1007/s11365-015-0368-1.

Elisa Ughetto

elisa.ughetto@polito.it

1 Politecnico di Torino, DIGEP, Corso Duca degli Abruzzi 24, 10129 Torino, Italy 


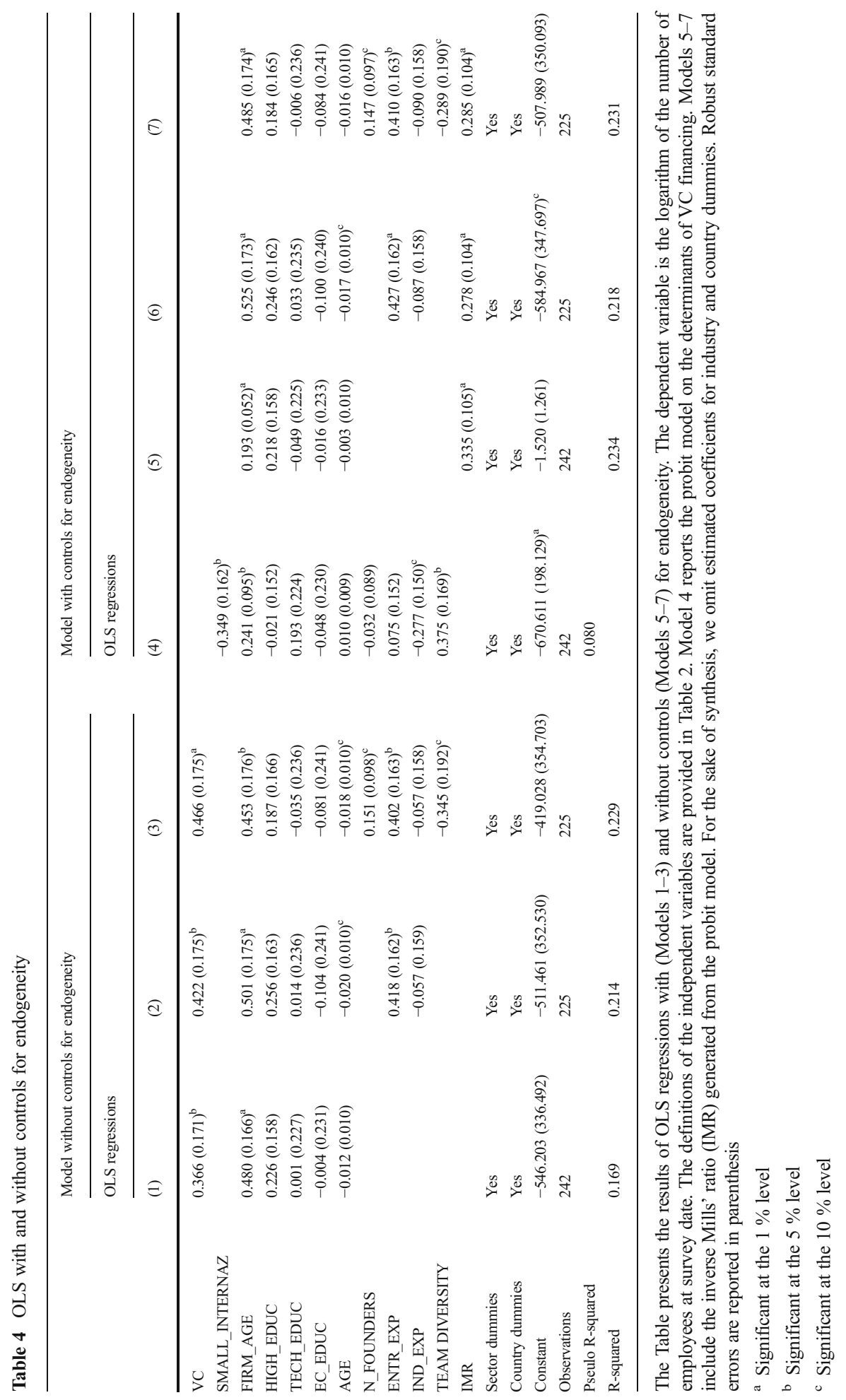

